\title{
CORRIGENDUM \\ Role of binary toxin in the outcome of Clostridium difficile infection in a non-027 ribotype setting - CORRIGENDUM
}

\author{
E. REIGADAS, L. ALCALÁ, M. MARÍN, A. MARTÍN, C. IGLESIAS AND \\ E. BOUZA
}

doi:http://dx.doi.org/10.1017/S0950268814001435. Published online: 29 June 2015.

In the above-mentioned article [1] there is an error in the Acknowledgements section. The correct version is given below:

We thank Thomas O'Boyle for his help in the preparation of the manuscript. This study was partially financed by Astellas Pharma Inc., the Rafael del Pino Foundation, and research Project number PI13/00687). from the Health Research Fund (FIS), of the Carlos III Health Institute (ISCIII), Madrid Spain, partially financed by the European Regional Development Fund (FEDER) 'A way of making Europe'. Elena Reigadas holds a grant from the Río Hortega programme of the Carlos III Health Institute, Spanish Government. The funders had no role in study design, data collection and analysis, decision to publish, or preparation of the manuscript.

The authors apologize for this error.

\section{REFERENCE}

1. Reigadas E, Alcalá L, Marín M, Martín A, Iglesias C, Bouza E. (2016). Role of binary toxin in the outcome of Clostridium difficile infection in a non-027 ribotype setting. Epidemiology and Infection, 144, 268-273. doi:10.1017/S095026881500148X. 